\title{
Adhesive Composites in Repairing Weapon Systems
}

\author{
T. Smal \\ Faculty of Management, Military Academy of Land Forces, Wroclaw, Poland
}

The manuscript was received on 17 August 2016 and was accepted after revision for publication on 24 November 2016.

\begin{abstract}
:
The article presents the classification and application areas of adhesives while repairing weapon systems, research on adhesive materials' durability, research on mechanical and strength properties of adhesive composites, research on durability of adhesive composites and methodology of their selection for expedient (temporary) repair in the field. The conducted research indicates certain constraints concerning the application of the examined adhesive materials. Consequently, any repairs provided with the use of adhesives should be in most cases only of temporary nature so that certain damage can be fixed quickly but only for a time of the particular task. It seems that the obtained research results, introduce issues of effective and efficient organization of the mentioned type of repair.
\end{abstract}

\section{Keywords:}

adhesive composites, field repairs, strength, durability, methodology of adhesives selection

\section{Introduction}

Adhesive materials may play a significant role in the process of weapon systems' repairs where an efficient and effective restoration of damaged objects to usability is an extremely important issue [1,2]. A great intensity of damage is especially visible during different kinds of tactical operations, such as military trainings, peacekeeping operations, or real combat actions. Repairs carried out in these conditions are called expedient repairs, and they do not necessarily aim at a permanent repair of full durability of the repaired part or the assembly, but rather at a quick restoration of the equipment efficiency in order to execute a task $[3,4]$.

With regard to a specific character of the military equipment field repairs, a repair should guarantee working life of a repaired object within the range from several dozens to several hundred hours, since after a task is executed or a combat operation is terminated, the damaged subassemblies can be replaced with new ones or regenerated

"Corresponding author: Faculty of Management, Military Academy of Land Forces, 51150 Wroclaw, Czajkowskiego 109, Poland,E-mail: t.smal@wso.wroc.pl 
in stationary repair workshops with the use of methods that restore their original durability and utilitarian properties $[2,5,6]$.

Based on the previous analyses, one should notice that the great potential within the scope of the use of adhesive materials in order to remove combat and utilization failures of military equipment is currently limited considerably by numerous organizational and technical problems. The most significant factors which either discourage or even limit the possibility of using adhesive materials are as follows:

- A great confusion and disinformation caused by a considerable number of companies offering different products, diversified nomenclature of the particular groups of adhesive materials offered on the market and encountered in the scientific literature; discretion of manufacturers and their technical and trade representatives in giving operational and strength parameters;

- The specific characteristics of adhesive materials which limit possibilities of their use; these are among others: aging processes, limited long-term strength, limited fatigue life, and low thermal stability. Since manufacturers of adhesives and adhesive composites advertise their products usually by only giving their short-term strength, it is difficult to decide whether or not the particular material fulfils the requirements of expedient (temporary) field repair.

In this context, the main research objectives are as follows:

1. To select a group of adhesive materials useful in performance repairs in the field and to conduct research on the selected adhesives in order to determine their mechanical and strength features, durability and utilitarian properties;

2. To analyse and synthesize the conducted research on adhesive materials, as well as to search for a correlation between the conducted experiments in the aspect of working out a simplified methodology of determining usefulness of the specific material for the military purposes.

\section{Classification of adhesives while repairing weapon systems}

In the scope of their use in order to repair weapon system failures, the division of adhesives with regard to their utilitarian properties and application seems to be the most significant. This division consists of the following groups of materials: structural, adhesive, coating, fibroplastic and special.

The adhesive materials that are especially useful in repairs are adhesives and adhesive composites which are most commonly manufactured on the basis of epoxy resins, as well as quick-setting anaerobic adhesives and silicon materials. The anaerobic adhesives serve for protecting screw joints against spontaneous unscrewing, and for fixing bushes, ball bearings, gears on shafts, as well as for sealing and bonding flat surfaces, such as housing and covers. These materials can replace solid seals; still, they are not suitable for seal repair. They are also useful for sealing slightly scratched flat surfaces. Additionally, silicon materials serve for bonding and sealing flexible joints, elements of low rigidity (covers, pans), as well as for sealing flat surfaces. Similarly to the previous materials, they can also replace solid seals; what is more, they can be used to mend damage in those elements [7, 8]. Epoxy adhesives and derivative materials created on their basis are of the widest application in technical equipment repairs. The epoxy adhesives are set with chemical methods after resin's (base's) reaction with a curing agent. The cross-linking takes place as the result of polyaddition, which is not accompanied with by-product release. In the group of epoxy adhesives one can distinguish hot-setting and cold-setting adhesives. The former 
indicate better strength properties; still, they require the setting temperature of 160 to $180{ }^{\circ} \mathrm{C}$ and the pressure of approximately $0.2 \mathrm{MPa}$. They are widely applied in manufacturing where there is a possibility to fulfil requirements of their application technology; still, they cannot be widely applied in military equipment field repairs with regard to exactly these requirements. Therefore, one should assume that only cold-setting epoxy adhesives may be applied in the field repairs of military equipment.

This kind of multi-purpose adhesive materials are adhesive composites, which form a special group used in repairs and regeneration of machine and devices' parts. The most common form of adhesive composites is paste (often very thick), and sometimes their forms are semi-liquid or liquid. The composites have got a lot of advantages; the most relevant are high temperature resistance (up to $150{ }^{\circ} \mathrm{C}$ ), a possibility of setting in low temperature (approximately $0{ }^{\circ} \mathrm{C}$ ), very good adhesion to metals, high resistance to erosion and mechanical wear, very high chemical resistance, high resilience, thixotropic features, no volume change during bonding, non-toxicity, non-combustibility, biological neutrality, great mixing tolerance, low thermal conductivity, long time of storing [9]. Due to the above enumerated advantages, the adhesive composites have been widely used to repair machines and devices, especially in situations where damage must be removed quickly. Therefore, the adhesive composites can be found, among others, in special repair kits which are used by technical services in the army [4, 10]. Apart from their numerous advantages, the adhesive composites are characterized by a number of specific properties which limit the possibilities of their application. These properties are, inter alia, relatively high sensitivity to bonding process conditions, limited long-term strength, limited fatigue life, low thermal stability, and aging processes [11-13].

The adhesive composites are also called "molecular metals", "polymer composites", or "resin-metal composites" in advertising materials and scientific publications. However, taking the definition of composite into account, according to which this is a material composed of a matrix and a filling in a form of fibres or particles, it seems that the most adequate and at the same time the simplest name which entirely signifies the specificity of the discussed materials is an "adhesive composite" term. Adhesive composites are materials which after setting are composed of a polymer matrix (most commonly it is an epoxy resin) and a filling in a form of particles.

Currently, a wide range of special adhesive composites of different purposes are produced. They could be divided into the following groups:

- "super metal" designed mainly for reconstructing losses of metal parts and characterized by good adhesion, high hardness, durability, and rigidity;

- "liquid metal" - materials of liquid consistency;

- „rapid” are characterized by a short time of setting;

- "slide" are characterized by a low coefficient of friction and that enables to use them with sliding surface repairs;

- "ceramic" materials protecting surfaces against erosion and cavitation wear;

- "elastomers" designed for rubber products' regeneration;

- "coating" materials (rustproof and protecting against wear).

In the above enumerated groups there can be different types of special materials, i.e. designed for repairing certain alloys (e.g. aluminium, brass) or characterized by higher thermal resistance. Furthermore, the manufacturers of adhesive materials recommend a wide range of accessories, such as: means for regenerated surface cleaning and degreasing, surface activators, separators (products protecting a surface 
against adhesive bonding), glass fibre nets (bands) designed for reinforcement of regeneration materials.

On the market there are numerous products of various companies which are known as: Belzona, Unirep, Chester Metal, Ciba Geigy, Loctite and lots of others. The products of the mentioned companies have got similar properties and applications. Taking the specificity of field repairs into account, it seems that the most useful are composites fulfilling the requirements of multi-purpose materials as "super metals" and those of quick-setting "rapid" type - they are Belzona 1111, Unirep 3 and Chester Metal Super, as well as Belzona 1221, Chester Metal Rapid and Unirep 1. Composites of more and more advantageous utilitarian properties are also appearing on the market. A good example of them can be Belzona 1831. According to the manufacturer, this composite can be applied on contaminated and wet surfaces since it has got especially modified composition thanks to which the composite is characterized by high adhesion to a surface despite not thorough cleaning of the surface before bonding.

Therefore, on the basis of conducted analysis, following adhesive composites were chosen for further experimental and numerical tests: Unirep 1 E Metal Rapid, Unirep 3 Super Metal, Belzona 1111 Super Metal, Belzona 1221 Super E-Metal, Chester Super Metal, Chester Rapid Metal. The chosen adhesive composites seem to be the best for specific mechanical repair of machines, vehicles and any equipment, particularly in the situation which determine short time of repair. Adhesive material Epidian 57/Z1 and Belzona 1812 were researched in order to compare its properties to selected adhesive composites.

\section{Research methodology of the selected adhesive composites}

The already executed assessment of adhesive composites' features makes it possible to narrow the scope of research which will be enable researchers to determine properties of new materials with regard to their use in expedient (temporary) field repairs. There is an assumption that these tests should be as easy to do as possible and their costs and duration should be limited to minimum [14]. Fig. 1 illustrates the specimens used to carry out the planned research.

In the first stage one should determine mechanical properties of an adhesive composite as a material, as $\sigma=\sigma(\varepsilon)$ relationship course, compression resistance $-R_{c}$ $[\mathrm{MPa}]$ and a modulus of longitudinal elasticity $-E[\mathrm{MPa}]$. As numerous experiments have proved, in case of this type of adhesive materials, it is most advantageous to execute this kind of determination by means of a compression-loaded cylindrical specimen since specimens undergoing stress and strain do not reach the level of deformations occurring in thin bonds [15]. Cylindrical specimens of $\phi=12.5 \mathrm{~mm}$ and $1=25 \mathrm{~mm}$ dimensions can be carried out by means of standardised syringes, which guarantee identical dimensions of specimens, as well as low costs and easy execution. During the execution of specimens one should make sure that there is no air bubble inside them; therefore, a greater amount of adhesive composite should be placed inside a syringe and then the excessive amount should be squeezed out by means of syringe's piston. Still, we should remember to ensure the right length of specimens by turning their ends by means of a lathe which also guarantees that bases of cylinders are perpendicular towards their walls. Similar cylindrical specimens can be also used to determine creep curves of the examined material in normal and increased temperatures $(\varepsilon=f(t))$. 
a)

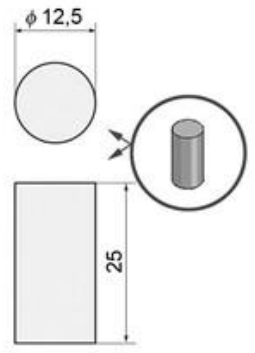

b)

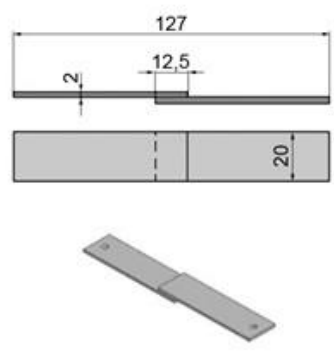

c)

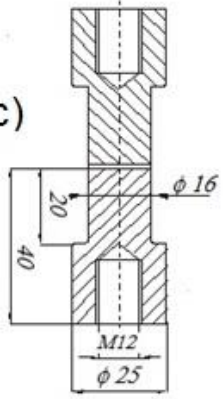

Fig. 1 Shape and dimensions of specimens used to determine properties of adhesives

Therefore, the first stage of research enables to define not only the cohesive strength of material but also the value of its modulus of longitudinal elasticity. As it is commonly known, the strength of shear-loaded adhesive joints $[7,16,17]$ that are the most frequently used joints is especially dependent on this mechanical property of a bond. What is more, the determined strength properties of adhesive composites are indispensable with carrying out possible simulations and numerical calculations by means of the finite-element method. On the other hand, the determination of creep curve enables to evaluate creep resistance of an examined composite, in other words its ability to transfer long-lasting static loads.

The subsequent (second) stage of research aims at the determination of strength properties of discussed adhesive composites in joints. As it results from the conducted experiments, this determination is the most advantageous by examining tensile strength of adhesive composites $R_{o}$ [MPa]. It is recommended to conduct the examination of this type by means of cylindrical specimens of $\phi=16 \mathrm{~mm}$ dimension which are frontally bonded and axi-symmetrically loaded. In joints of this kind of specimens there is stress similar to uniaxial tension. Depending on the type of destruction of an adhesive bond (adhesive or cohesive) by means of these specimens, the value of generalized destructive forces of adhesion or cohesive strength of examined material of bond (short-term strength) can be determined. Therefore, the determination recommended in this stage enables to define general strength properties of an examined adhesive composite, and also to compare adhesive resistance of different materials and determine whether their destruction is of an adhesive or cohesive type. If adhesive destruction is found, it means that the examined material shows low adhesion to an adherent surface and it can show lower long-term static and fatigue resistance. The proposed determination also enables to define dependence of the particular material's adhesion forces on the method of preparing a surface for joining.

The final proposed stage of research is optional. It will be used when there is a necessity to determine additional properties of adhesive composite connected with defining its strength in the conditions specific for the particular type of adhesive composite or conditions of its application, e.g. determining the influence of temperature conditions of joint curing or operation on its strength, or determining the influence of natural aging on its strength properties. It seems that it is most advantageous to use shear single lap joints which enable generalized assessment of strength properties of examined material for this type of research $[18,19]$ and this is the most commonly used determination in order to define adhesive strength. It is recommended 
to conduct this research in accordance with PN-EN 2243-1:1999, by which the length of a lap is $12.5 \mathrm{~mm}$, and its width is $25 \mathrm{~mm}$. In the research of this type, the method of preparing the surface for joining that would correspond with actual conditions of repair should be used.

\section{Research on mechanical properties of adhesive composites}

On the basis of experimental research and calculations concerning stresses in an adhesive layer it could be stated that in these joints there are much greater levels of stresses and deformations than in flat specimens created from adhesive materials [18]. Therefore, in case of adhesive composites it is more advantageous to determine compression curves by means of cylindrical specimens since this kind of research is characterized by great repeatability of research results and the great range of strains [20], so stress-strain curves were determined on the basis of compression of cylindrical specimens in ZD-10 testing machine with the load increase speed of approximately $500 \mathrm{~N} / \mathrm{s}$. On the basis of the determined stress-strain curves, the moduli of elasticity and compression strength of the examined adhesive composites were defined (Fig. 2). This kind of tests enables also to determine the value of modulus of longitudinal elasticity of the examined material. As it is well-known, the strength of adhesive joints with shear strain (the most commonly used joints) is considerably dependent on this particular mechanical property of the joint [17].

According to Volkersen's analysis, in case of single-lap joint of two elements of the same tensile stiffness, the strength of the joint can be described with the following relation:

$$
P=\tau_{n} b \sqrt{\frac{2 \delta_{k} \delta E}{G_{k}}} \frac{\sinh m l}{\cosh m l+1},
$$

where $m=\sqrt{\frac{2 G_{k}}{\delta_{k} \delta \cdot E}}$,

$E \quad-$ the modulus of longitudinal elasticity of bonded elements,

$G_{k} \quad-$ the modulus of shape elasticity of an adhesive layer,

$b \quad-$ the breadth of an adhesive joint,

$l \quad-$ the length of an adhesive joint,

$\tau_{n} \quad-$ the shear failure stress of an adhesive layer,

$\delta \quad-$ the thickness of a bonded element,

$\delta_{k} \quad-$ the thickness of an adhesive layer,

$\sin h$ - hyperbolic sinus,

$\cos h$ - hyperbolic cosines.

The relation describing the strength of lap bonding for the length of a lap bigger than a limiting lap is simplified to the following form:

$$
P=\tau_{n} b \sqrt{\frac{2 \delta_{k} \delta E}{G_{k}}} .
$$

There is a well-known relation between the modulus of shape elasticity and the modulus of longitudinal elasticity:

$$
G_{k}=\frac{E_{k}}{2(1+v)}
$$


where $v$ - Poisson's ratio.

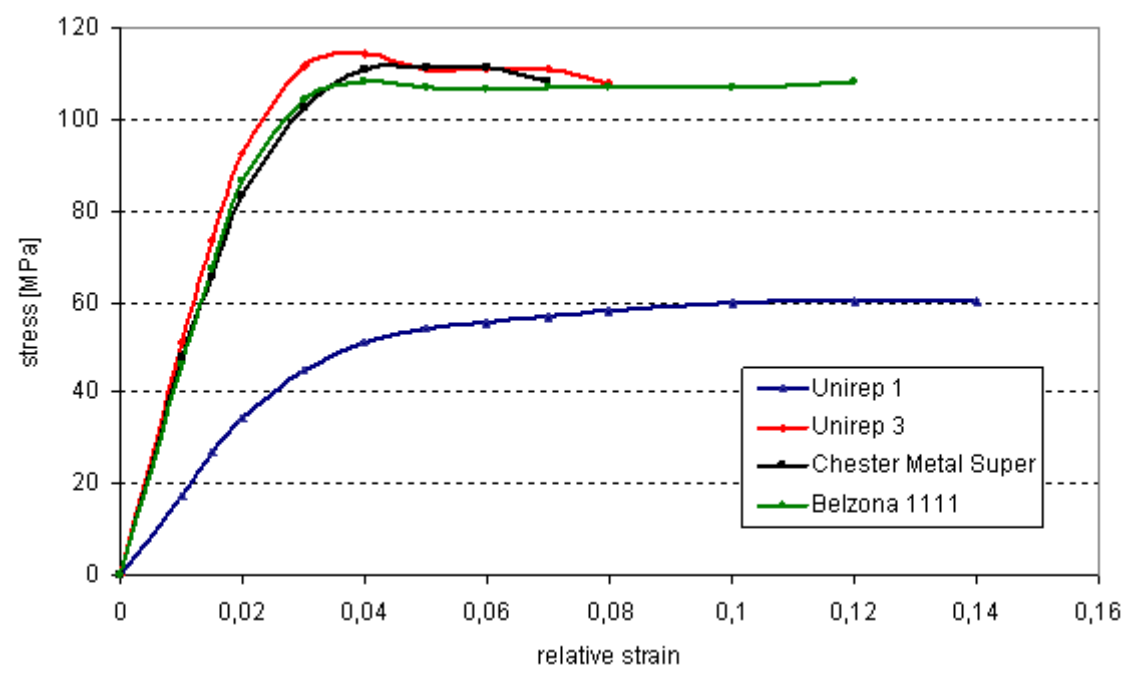

Fig. 2 Exemplary compression curves of adhesive composites gained with the cylinder specimens

The determined results make it possible to state that mechanical properties of the three examined adhesive composites of the so-called "super metal" group (Unirep 3, Belzona 1111 and Chester Metal Super) are similar. They show similar compression strength of approximately $110 \mathrm{MPa}$ and similar values of the modulus of longitudinal elasticity 4400 to $5100 \mathrm{MPa}$. The properties of the examined adhesive composites of "rapid" group are much different from the materials of the "super metals" group. The former are characterized by less compression strength and less values of moduli of longitudinal elasticity. Mechanical properties of examined adhesive composites significantly differ from one another as well. Chester Metal Rapid has the compression strength $R_{c} \approx 95 \mathrm{MPa}$ and the modulus $E \approx 4350 \mathrm{MPa}$, Belzona 1221 has $R_{c} \approx 72 \mathrm{MPa}$ and $E \approx 2270 \mathrm{MPa}$ and Unirep 1 has $R_{c} \approx 60 \mathrm{MPa}$ and $E \approx 1840 \mathrm{MPa}$.

\section{Research on short-term strength of adhesive composites}

A great deal of research has proven that the measure of adhesion, i.e. the adhesive forces of an adhesive material in relation to an adhesive surface, can be the value of normal failure stresses perpendicular to this surface [20,21]. Therefore, to determine the adhesive properties of the adhesive composites one can use frontally joined specimens, with tensile load. This kind of specimens makes it possible to determine a type of joint's damage (cohesive, adhesive or mixed) and to estimate adhesive and cohesive forces. Since the adhesive strength of a joint is not only dependent on adhesive properties of the material, but also on the way of preparing of an adjacent surface to the material, one should keep in mind that surfaces of specimens should be prepared in the way similar to the way that can be used in the future possible repairs.

In order to verify the influence of the type of bonded materials on strength properties of composites, specimens of aluminium alloy (2024TR), steel (S235Jr) and brass were used. The gained results make it possible to claim that the examined composites 
indicate different strength to tensile depending on the joined material (Fig. 3). Adhesive materials of the "super metal" group show comparable adhesive properties. All joints created with the adhesive composites of this group have sustained cohesive damage. The joints of the adhesive composites of the "rapid" group generally have sustained adhesive damage; this clearly shows their lower adhesive properties. The adhesive composites of the "rapid" group show definitely better adhesion to steel than to aluminium alloy. Out of the three of the examined materials of the "rapid" group, Chester Metal Rapid shows visibly better strength properties (adhesive and cohesive) than the other two.

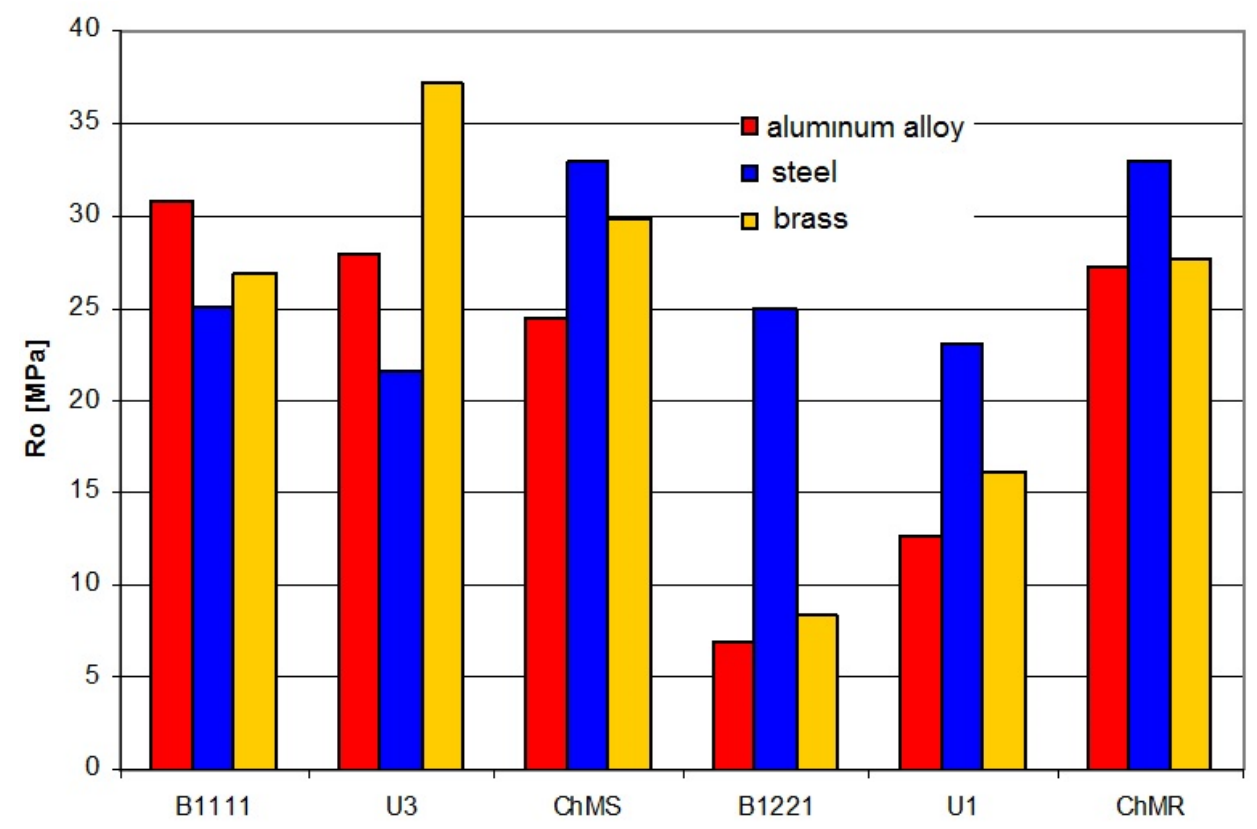

Fig. 3 Tensile strength of adhesive composites for different types of bonded materials

Joints of the highest significance among adhesive joints are those with shear strain. Therefore, estimation of strength properties of adhesive composites should consist in determining their ability to transfer loads in these kinds of joints $[17,19$, 22]. One could notice that the highest value of shear strength in the "super metal" group is the feature of Belzona 1111 and Chester Metal Super composites; in the "rapid" group this is the feature of Unirep 1 (Fig. 4). In case of Belzona 1111 and 1221 composites there was only a cohesive failure of a joint, while with other materials there were both cohesive and adhesive failures of joints.

Adhesive composites are manufactured and stored before use in a doublecomponent form (basis + curing agent). Using the example of Unirep 3 adhesive composite, it was verified which of the components of this adhesive material had crucial influence on lowering of its strength properties after long-lasting storage [23]. It turned out that a component that degraded to the greater extent, and therefore, which was responsible for lowering of properties of adhesive composite, in case of Unirep 3, was the curing agent. 


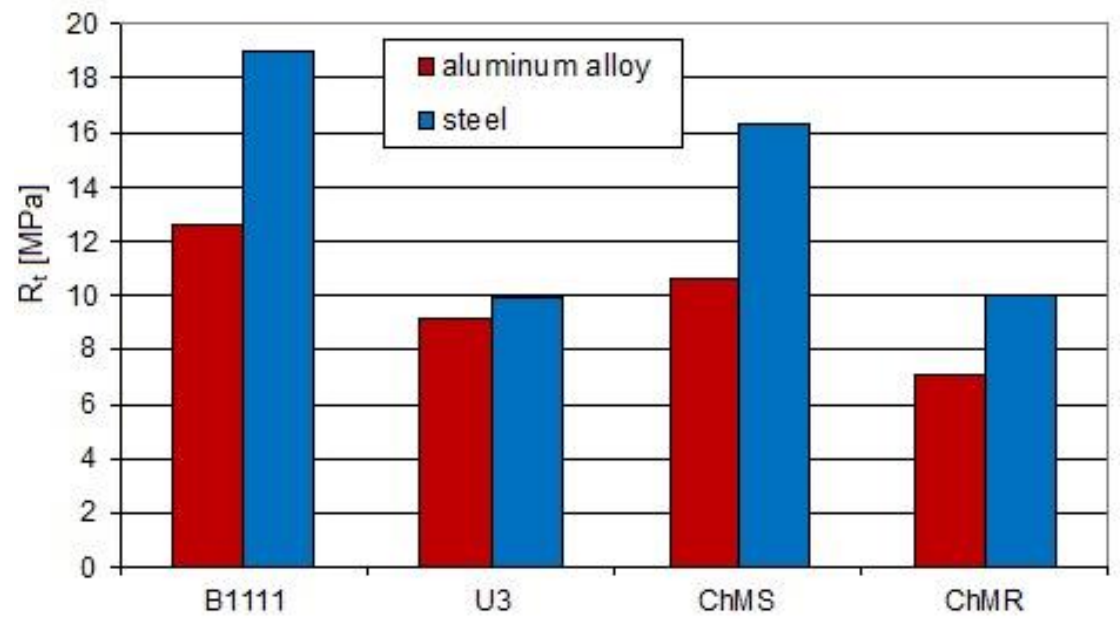

Fig. 4 Shear strength of adhesive composites

\section{Research on long-term strength of adhesive composites}

The manufacturers of adhesive materials very rarely define durability of their products to long-term loads $[24,25]$. A credible method of determining long-term strength of adhesive joints is conducting an experimental analysis. Still, it involves considerable costs and time-consuming research.

It was decided to estimate permissible values of loads of the adhesive composites with regard to their static long-term strength. On the basis of detailed methodology used in the work [26], creep curves for the selected adhesive composites were determined. In order to define the influence of curing conditions of adhesive composites on their long-term strength, the curing was carried out by single-stage (in room temperature) and by double-stage [27] (in increased temperature). On the basis of the previous experiments it seemed that ambient temperature was too low to gain high long-term strength of materials based on epoxy resins [28]. It seems that this state of facts is related to a level of cross-linking of a material. The material cured in the increased temperature is characterized by a higher level of cross-linking. Therefore, it has got different physical and mechanical properties. The research showed that some adhesive composites were characterized by a rapid increase in strains in the increased temperature that caused permanent deformations or destruction of the tested specimen within several or several dozen minutes from commencement of the measurement (Fig. 5). As a result, these materials were excluded from the further examination.

In order to determine durability of lap joints, experimental research was conducted; it was preceded by defining their short-term strength - on its basis the loads for long-term research were selected. The measure of durability of lap joints executed with the use of adhesive composites was a lapse of time between the commencement of research and specimen destruction [29]. With regard to the assumed expediency of repairs, 500 hours were the assumed maximum time of test. The research was conducted at the temperatures of 60,80 and $100{ }^{\circ} \mathrm{C}$ (possible operational temperature of the repaired elements was taken into consideration). 


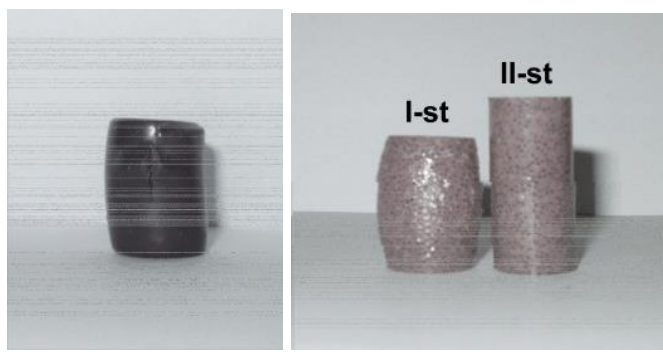

Fig. 5 Unirep 1 and Belzona 1812 (after 1. stage curing) adhesive composites after a few minutes from the moment of $30 \mathrm{MPa}$ load in the temperature of $60^{\circ} \mathrm{C}$

Joints made of Belzona 1111, Chester Metal Super, Unirep 3, and double-stage cured Belzona 1812 composites were characterized by durability of $500 \mathrm{~h}$ at the temperature of $60{ }^{\circ} \mathrm{C}$. Since the durability of adhesive joints did not change considerably at the temperature of $80^{\circ} \mathrm{C}$ either, further research was conducted at the temperature increased to $100{ }^{\circ} \mathrm{C}$ (Fig. 6).

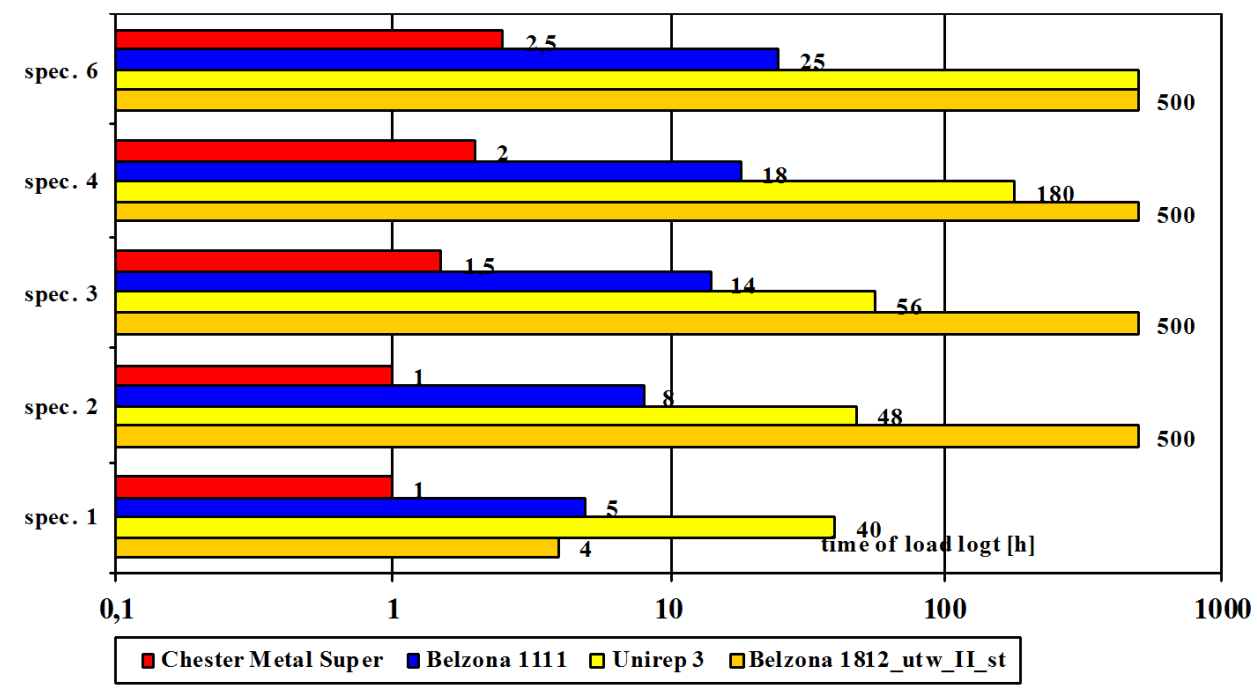

Fig. 6 Static long-term strength of lap joints bonded with different adhesive composites (load with power of $60 \% P_{n}$ and temperature of $100{ }^{\circ} \mathrm{C}$ )

At the temperature of $100{ }^{\circ} \mathrm{C}$, most of the examined specimens were destroyed before the assumed time of $500 \mathrm{~h}$. The first destroyed specimens were made of Chester Metal Super. Specimens made of Belzona 1111 were destroyed within the first day and night. Better durability was shown by specimens made of Unirep 3 as they remained intact from several dozen to several hundred hours; one of the examined specimens was not destroyed within the assumed $500 \mathrm{~h}$. The specimens made of double-stage cured Belzona 1812 showed the best durability - this material is designed for operation in the increased temperature.

The considering adhesive composites were researched by Godzimirski on fatigue life [18] using tensile loaded cylindrical specimens (comp. Fig. 2). During the research, the destruction of cohesive type was noticed in case of every examined specimen made of Belzona 1111. What is more, it was stated that the examined com- 
posite was characterized by longer fatigue life in comparison with Epidian 57/Z1 subject to adhesive destruction. The examined joints made of Chester Metal Super composite showed long fatigue life, despite the fact that Chester Metal Super material itself is characterized by a short fatigue life, and that indicates no correlation between the fatigue life of the material itself and tensile loaded joints made with this material. The most probable reason for this state of facts is a relatively high stress-strain strength of this material [30]. The conducted research also showed that the fatigue life of examined Chester Metal Super composite in bonds of tensile loaded joints was rapidly decreasing with an increase of maximum load of a fatigue cycle from approximately 0.5 to approximately 0.6 of short-term strength. With Chester Metal Rapid composite there was a shorter average fatigue life of joints in relation to the composites of "super metal" group, that is Belzona 1111 and Chester Metal Super. This fact was probably caused by adhesive destruction of joints (Fig. 7).

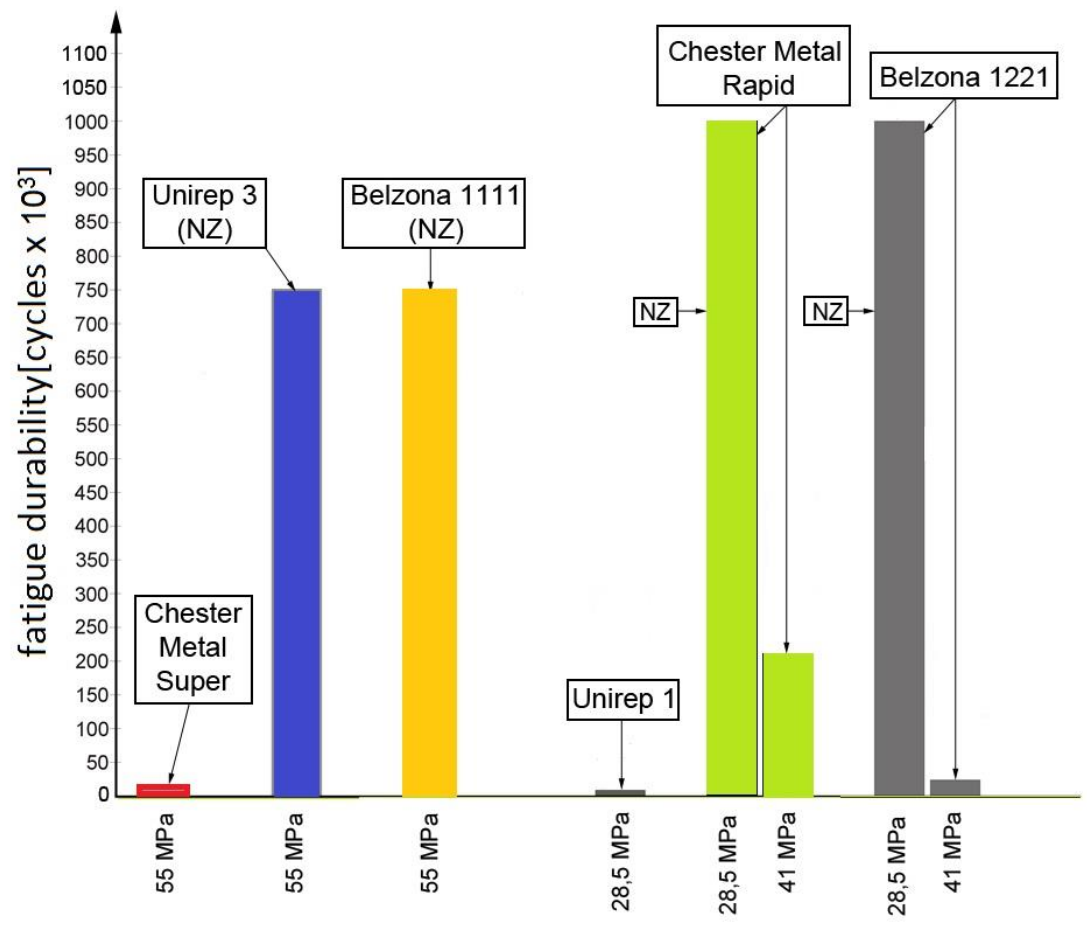

Fig. 7 Fatigue durability of tested adhesive composites

(NZ - specimen was not damaged during the test) [18]

Additionally, the discussed materials were subjected to a fatigue life test in single-lap joints (comp. Fig. 2). The fatigue life of Belzona 1111 composite material in lap joints turned out to be longer than this of Chester Metal Super material contrary to the situation with frontal joints. In Fig. 8 the fatigue lives of specimens loaded with identical cycles and joined with different adhesive composites were compared [2].

The shortest life was visible with specimens joined with Chester Metal Rapid. Still, their relative load was the greatest. Belzona 1111 and Epidian 57/Z1 are characterized by long absolute fatigue life with the applied load. 


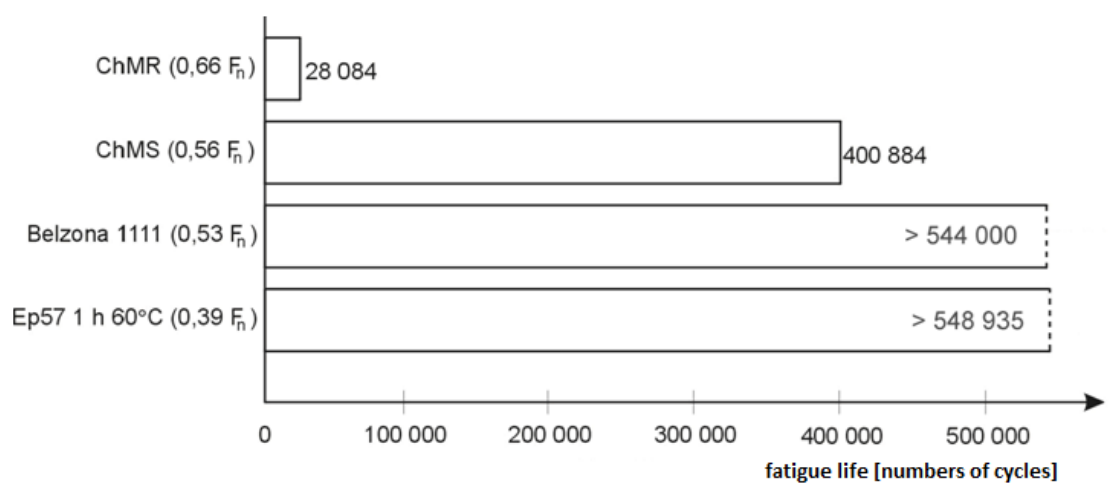

Fig. 8 Comparison of absolute shear fatigue life (the maximum load of a fatigue cycle was $1.3 \mathrm{kN}$ ) of adhesive composites

\section{Research on selected utilitarian properties of adhesive composites}

The analysis of the results indicates that the tested adhesive composites are characterized by different short-term strength in the increased temperature (Fig. 9). With this regard, the best properties were shown by Belzona 1111 adhesive composite which even at the temperature of $180{ }^{\circ} \mathrm{C}$ was characterized by strength at the level of approximately $5 \mathrm{MPa}$. Similar strength was reached by Unirep 3 composite in the temperature slightly over $100{ }^{\circ} \mathrm{C}$; in the case of Chester Metal Super it was approximately $130{ }^{\circ} \mathrm{C}$. Furthermore, Belzona 1111 and Unirep 3 adhesive composites also showed an increase in shear strength at the temperature of $60{ }^{\circ} \mathrm{C}$; in the case of Belzona 1111 , the increase was also in $100{ }^{\circ} \mathrm{C}$. It can be explained by a decrease in modulus of elasticity of these materials at the increased temperature.

The conducted research makes it possible to state that the existing limitations of using the examined adhesive composites with regard to the increased temperature are connected to the method of their loading. If the criterion of possibility of using a certain composite adhesive in repair is its stiffness, then the examined materials should not be used at the temperature higher than 70 to $80^{\circ} \mathrm{C}$. If the criterion of possibility of their using is their strength in joints, then Belzona 1111 composite can be used even up to the temperature of 120 to $140{ }^{\circ} \mathrm{C}$.

\section{Repair technology and methodology of adhesive composites selection}

Considering the conducted analyses and syntheses, the following conclusions can be drawn:

1. There are many methods which can be used to execute repairs in the field conditions, but it seems that the adhesive materials have a great potential of providing such actions. They not only have numerous advantages of adhesive joints, but they might also increase capacities of the particular links of the repair system such as reducing work consumption, enabling performance of some repairs on a lower level. Additionally, there is no necessity to use expensive spare parts and to be dependent from their delivery. 


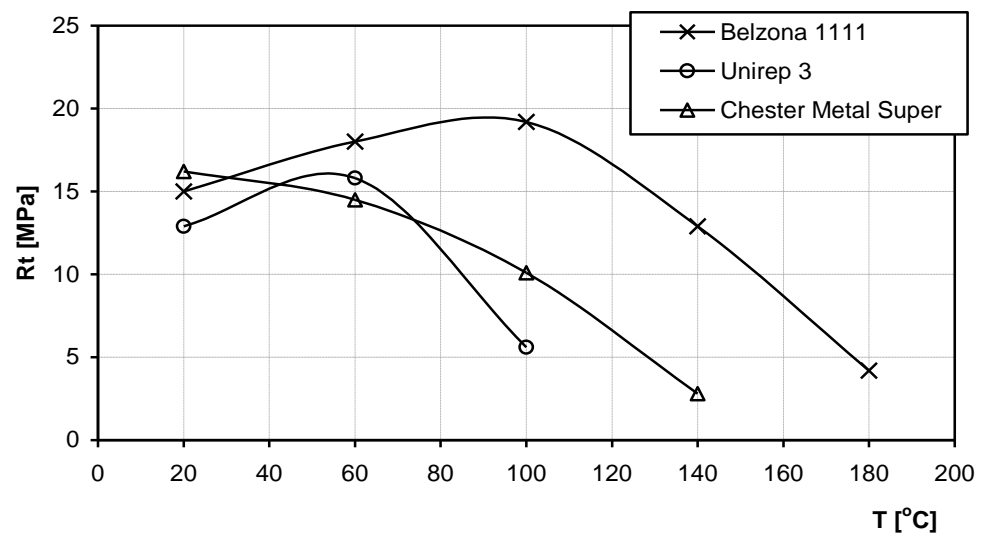

Fig. 9 Shear strength of joints bonded with adhesive composites at the increased temperature

2. The modern adhesive composites may provide solutions to many problems which can occur as a result of intensive exploitation of the military equipment, as well as an influence of the enemy's munitions. There are lots of products of numerous companies, but taking the specificity of field repairs into account, it seems that the most useful are the composites meeting the requirements of multi-purpose materials as "super metals" and those of quick-setting "rapid" type.

3. The adhesive composites applied to field repairs of weapon systems must be able to transfer great loads and create solid construction joints. Therefore, they are expected to show high cohesion and adhesion. These parameters can be increased in case of the examined adhesive composites through:

- Modelling the joint in a way that it resists shear or compression, and adhesive layer thickness is approximately 0.12 to $0.2 \mathrm{~mm}$ in case of shear;

- Proper preparation of a surface for bonding by sandblasting or with an abrasive paper, as well as applying recommended solvents for surface cleaning before bonding;

- Proper preparation of an adhesive composition through careful measuring and mixing of components;

- Heating up a bonded surface and an adhesive composition after applying it to a damaged spot in case of low ambient temperatures. Moreover, the time of adhesive composites setting may be effectively shortened by increasing the curing temperature.

4. The conducted analyses also proved that the adhesive composites can be used in the field conditions only if their specific features are taken into consideration. Therefore, only materials which ensure maximum compliance with the requirements of such repairs should be taken into consideration.

Taking into account all the factors which influence predicting of adhesive joints strength, it can be assumed that algorithm of an adhesive composite selection is a complex process. According to a heuristic model of predicting adhesive joints strength presented by Kuczmaszewski [19], this process can be considered in a few 
stages, such as optimizing of construction, technology and maintenance. As far as the researched adhesive composites and their use to execute expedient repair of weapon systems are concerned, all factors which should be taken into account can be divided into 5 groups:

1. Defining loads (static or fatigue, short or long-term, impact load, etc.).

2. Defining working conditions (temperature, humidity, impact of fluids, time, etc.).

3. Defining geometric characteristic of a damaged zone (type and dimension of damage, adhesive thickness, etc.).

4. Defining adhesive composite properties (modulus, thermal expansion, durability, grindability, absorptivity, etc.).

5. Defining technology (surface preparing, adhesive preparing, temperature and time of curing, pressure of curing, etc.).

However, while executing expedient repairs in the field conditions, it is impossible to include all factors mentioned above. What is more, there is also no need to include most of them taking into account the temporary nature of such repairs. Therefore, only the most important factors should be considered when designing algorithm of adhesive composites selection in order to simplify the selection of procedures as much as possible.

The chosen factors can be divided into two groups. The first group will have qualifying nature, so it will determine whether adhesive composite could be used for the repair at all. The group should include the following factors: time to complete the repair, temperature of curing (ambient temperature), temperature of work, possibilities of proper preparation of surface for bonding. The second group of factors will help to select proper adhesive and determine maximum operating time of repaired part.

Taking into account the above assumptions, the proposed algorithm of adhesive composites selection is presented in Fig. 10. The further presented proposition is based on the assumption that a person who will use this algorithm is trained in using adhesives and assessing conditions of their work.

It should be noted that the proposed algorithm includes only basic group of the researched adhesive composites, which are "super metal" and "rapid". If we also consider other sorts of adhesive composite such as intended for higher temperature (Belzona 1812) and provide it with appropriate curing conditions (temperature of curing 50 to $60{ }^{\circ} \mathrm{C}$ within few hours), this composite could be used to repair components whose temperature of work is higher than $100{ }^{\circ} \mathrm{C}$. At the same time, if we consider other special adhesive composite intended for wet surfaces (Belzona 1831), this composite could be used to repair parts which cannot be properly cleaned before repairing, but only in case of lightly loaded parts. However, it is obvious that in terms of field conditions and combat operation such analyses are very difficult to conduct.

\section{Conclusions}

The analyses introduced in the article enable researches to draw following assumptions and practical conclusions:

1. Mechanical and strength properties of the three examined composites of the "super metal" group were similar. Still, Belzona 1111 composite was characterized by slightly less value of modulus of longitudinal elasticity and the highest tensile and shear strength. Moreover, this composite showed the highest aging resistance in natural conditions. 


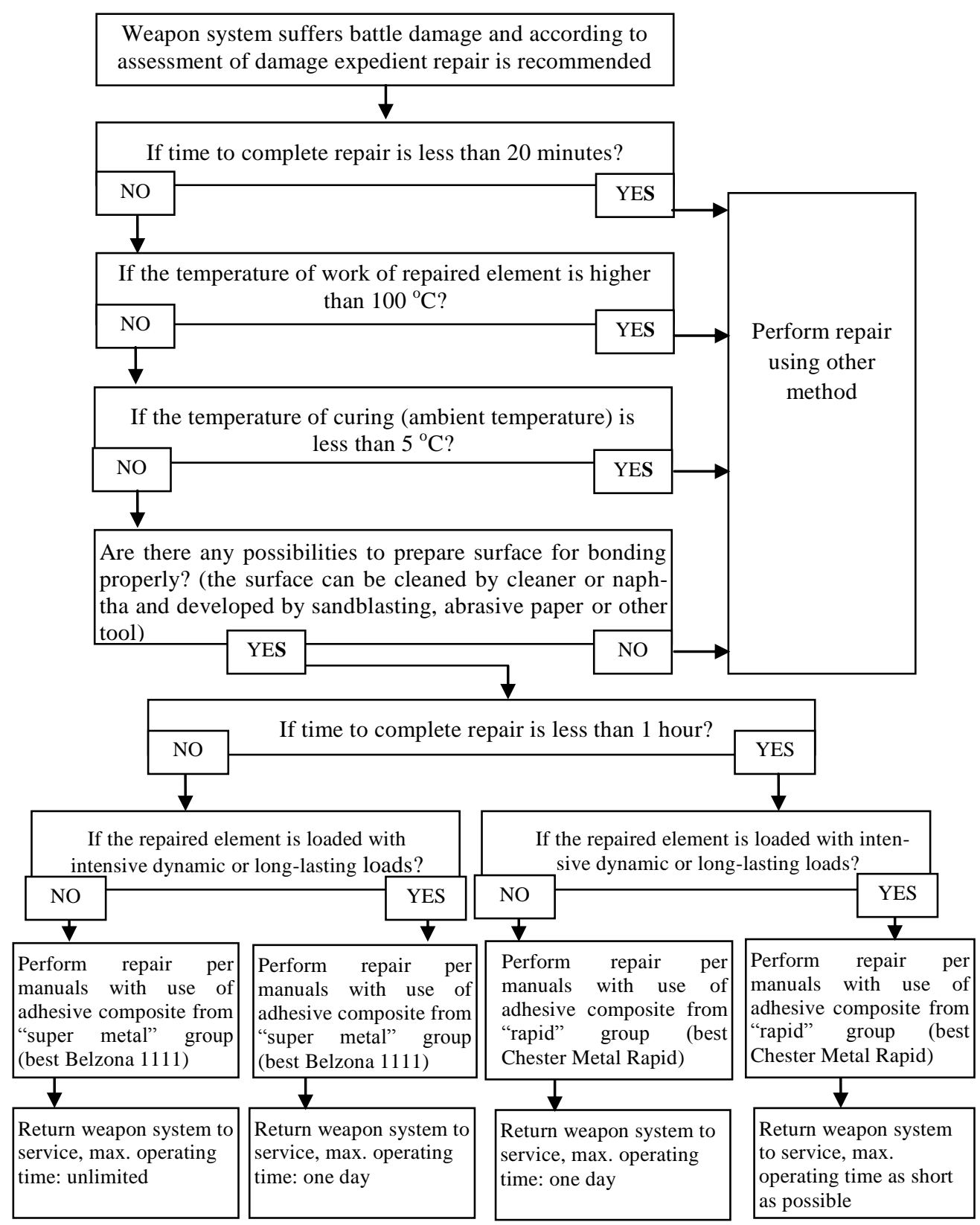

\section{Fig. 10 Chart of adhesive composite selection to execute expedient (temporary) repair in field conditions}

2. Mechanical and strength properties of the three examined composites of the "super metal" group were similar. Still, Belzona 1111 composite was characterized by slightly less value of modulus of longitudinal elasticity and the highest 
tensile and shear strength. Moreover, this composite showed the highest aging resistance in natural conditions.

3. Mechanical and strength properties of adhesive composites of the "rapid" group were non-comparable. Out of the examined adhesive composites of the "rapid" group, Chester Metal Rapid showed clearly better strength properties and fatigue durability.

4. On the basis of the conducted research, it is hard to formulate unambiguous recommendations concerning optimal temperature conditions of curing of adhesive joints made of adhesive composites. On the one hand, the increased temperature of curing can reduce short-term strength of a joint (through increasing the level of cross-linking, and in this way, through increasing modulus of elasticity of adhesive composite); on the other hand, it causes an increase in static and fatigue durability of adhesive joints. Still, one can express a general recommendation according to which the curing of joints should be executed at the expected temperature of operation, but not higher than the recommended operating temperature of the adhesive composite.

5. With regard to the requirements of repairs executed in field conditions (expediency of repairs), the long-term strength of adhesive joints higher than 50 hours and fatigue strength of adhesive joints higher than 100000 cycles can be accepted as sufficient in most of the cases. Therefore, the safe value of maximum fatigue loads of adhesive composites that ensures the required durability of joints made of these composites, should be the load of 0.5 of failure load in static tests of short-term strength.

6. While executing expedient repairs in the field conditions, it is impossible to include all factors which have an influence on adhesive composites' strength. Therefore, only the most important factors should be considered when designing the algorithm of the adhesive composites' selection in order to simplify the selection procedures as much as possible. The most important factors which should be taken into consideration are as follows: time to complete repair, temperature of curing (ambient temperature), temperature of work, possibilities to properly prepare the surface of a repaired zone for bonding and loads. Based on the mentioned factors and conducted research, it is possible to assess maximum operating time of a repaired part.

\section{References}

[1] CYPHERS, D. Battle Damage Assessment and Repair (BDAR) Capability Improvement Program. Aircraft Survivability 2007, No. Summer, p. 9-11. [cited 2009-05-12]. Available from: <https://jaspo.wpafb.af.mil/>.

[2] GODZIMIRSKI, J. et al. Epoxy adhesives. An application in repairs of machines and equipment (In Polish). Warsaw: WNT, 2010.

[3] FICOŃ, K. Operational logistics (In Polish). Warsaw: BEL Studio Sp. z o.o., 2004.

[4] FM 4-30.31 (FM 9-43-2): 2006, Recovery and Battle Damage Assessment and Repair.

[5] DAVIS, M. J. and BOND, D. Principles and practices of adhesive bonded structural joints and repairs. International Journal of Adhesion \& Adhesives, 1999, no. 19, p. 91-105. 
[6] STANAG 2418: 2009, Procedures for expedient repair, including battle damage repair.

[7] DA SILVA, LFM., ÖCHSNER A. and ADAMS RD. (Eds). Handbook of Adhesion Technology. Berlin: Springer 2011.

[8] KINLOCH, AJ. Adhesion and Adhesives: Science and Technology. London: Chapman and Hall, 1987.

[9] Information and repair catalogues of products: Belzona, Chester Metal, Unirep.

[10] SMAL, T. and FURCH, J. Expedient Repairs - Analysis of Possibilities and Needs. Advanced in Military Technology, 2011, vol. 6, no. 2.

[11] DAVIS M. J. A call minimum standards in design and application technology for bonded structural repairs. In Proceedings of International Conference entitled: Composite Repair of Aircraft Structures. Vancouver, 1995, p. 4-15.

[12] ROŚKOWICZ, M. and SMAL, T. Numerical - experimental analysis of durability of adhesive joints loaded in raised temperature conditions. Problems of Machines Operation and Maintenance, 2008, vol. 43, no. 1 (153), p. 73-87.

[13] SMAL, T. Strength of glue joint aged in natural climatic conditions (In Polish). Bulletin of the Military University of Technology, 2005, no. 5-6 (633-634), p. 121-127.

[14] SMAL, T. Methodology of assessment of adhesive composites' properties. Polymers 2013, no. 1, p. 114-120.

[15] GODZIMIRSKI, J. and SMAL, T. Research on possibilities of making repairs with use adhesive materials (In Polish). Problems of Machines Operation and Maintenance, 2000, vol. 35, no. 4 (124), p. 199-212.

[16] BRONIEWSKI, T., KAPKO, J., PŁACZEK, W. and THOMALA, J. Research methods and estimation of properties of synthetic materials (In Polish). Warsaw: WNT, 2000.

[17] GODZIMIRSKI, J. Short-term strength of structural adhesive joints (In Polish). Warsaw: WNT, 2002.

[18] GODZIMIRSKI, J. (Eds.). Strength of adhesive joints (In Polish). Warsaw: Military University of Technology, 2009.

[19] KUCZMASZEWSKI, J. Fundamentals of metal-metal adhesive joints design. Lublin University of Technology. Lublin: Polish Academy of Science, 2006.

[20] GODZIMIRSKI, J., KOMOREK, A. and SMAL, T. Research of strength features of adhesive composites (In Polish). Maintenance Problems of Machines, 2007, no. 1 (64), p. 157-165.

[21] GODZIMIRSKI, J. and TKACZUK, S. Numerical modeling of adhesive bonds (In Polish). Mechanical Review, 2005, no. 9, p. 32-35.

[22] MESSLER, RW. Joining of Materials and Structures. Oxford: Elsevier Incorporation, 2004.

[23] SMAL, T. Research on strength properties of composite adhesives in connection to period of their storage (In Polish). Technology and Assembly Automation, 2004, no. 3, 4 (45, 46), p. 101-103. 
[24] MESHGINA, P., CHOIB, KK. and REDA TAHA, MM. Experimental and analytical investigations of creep of epoxy adhesive at the concrete-FRP interfaces. International Journal of Adhesion and Adhesives, 2009, no. 29.

[25] ROŚKOWICZ, M. Long-lasting strength of adhesive bonds (In Polish) [PhD Thesis], Warsaw: Military Academy of Technology, 2004.

[26] SMAL, T. and ROŚKOWICZ, M. Experimental and numerical analysis of adhesive composite long-lasting strength (In Polish) [Research Report]. Wroclaw: The gen. Tadeusz Kosciuszko Military Academy of Land Forces, 2006.

[27] ROŚKOWICZ, M. and SMAL, T. Determination of creep curves and long-term strength of adhesive joints (In Polish). Technology and Assembly Automation, 2007, no. 2, 3 (56, 57), p. 120-123.

[28] ROŚKOWICZ, M. and SMAL, T. Modification influence of adhesive layer on static long-lasting life of adhesive joint (In Polish). Technology and Assembly Automation, 2006, no. 2 (52), p. 51-54.

[29] ROŚKOWICZ, M. and SMAL, T. Static long-lasting life of adhesive composite in shear loaded joints (In Polish). Technology and Assembly Automation, 2007, no. $2,3(56,57)$, p. 112-115.

[30] GODZIMIRSKI, J. and SMAL, T. Possibilities of adhesive joints executing with use of composite adhesives (In Polish). Technology and Assembly Automation, 2000 , no. 3 (29), p. 18-23. 